\title{
Landscape, memory and contemporary design
}

\section{Panita Karamanea}

Abstract Simon Schama in Landscape and Memory says, 'Before it can ever be a repose for the senses, landscape is the work of the mind. Its scenery is built up as much from the strata of memory as from layers of rock' (1995: 6-7).

Landscape and memory are concepts that are strongly interwoven in the identity of a place and its inhabitants. For the teaching and practice of landscape architecture, 'landscape identity' is regarded as an important issue of special conceptual value.

This essay explores the way that landscape, identity of a place and memory interact through design and design's visual form. It is divided into two parts. The first explains conceptual approaches to landscape as a palimpsest of actions on territory, as a dynamic 'archive', and as a tangible link between what we are and what we have become. The second part is focused on a review of three examples of design from professional and educational case studies. The rationale for presenting the particular projects is that each one explores the relationship between identity, memory and landscape design to address three questions: How can we activate latent characteristics of a landscape that are connected and refer to past times? How can contemporary landscape design rethink the past and reveal the subtle traces left at an historical or archaeological place? How does memory, as a mind process, inflect our perception of landscape and influence our interventions and thoughts about it?

In order to conceive integrated proposals that are not imposed on or do not alter the site radically, all three projects try to activate the inherent qualities of each place. They propose spaces that host a resilient coexistence of architectural and natural elements using subtle gestures and ecology as the main design tools. They are landscape projects that try to awaken, to reveal, to underline by subtraction the strongest elements that form the identity of a place and to achieve these aims within a biological framework.

\section{Introduction}

Paysage est ou le ciel et la tierre se touchent

-Michel Corajoud

Landscape architecture can be considered as a lens for understanding a site and enriching spatial creations. It is a broad field that refers to the parameters, tensions and dynamics that create space in an ever-changing system 
of relationships. This essay explores the way that landscape as a subject of research, the identity of a place and memory interact through design and its visual and material form.

Divided into two parts, the first explains conceptual approaches to landscape as linked to place, identity and memory, and examines concepts of genius loci and collective memory. If we consider designs as hypotheses made about sites, can collective memory and genius loci form an opportunity for intervening? The second part of the essay is focused on a review of three design examples from professional and educational case studies. The rationale for presenting these projects is that each one of them responds to the above question of how to interrelate identity and memory with landscape design.

The first example, located in the historical centre of the city of Thessaloniki, refers to the redesign of an urban square that witnessed dramatic events during the Second World War. The second example has to do with the redesign of the surroundings of a protected monument in the same city. The third example presents a diploma student project that focused on enhancing through design the archaeological site of a sacred necropolis in Crete.

An urban landscape in the centre of an historical city, a landscape surrounding a monument in the suburbs, an archaeological landscape in the countryside of an island-three completely different landscapes that provoke the same questions: How can we activate latent characteristics of a landscape that are connected and refer to past times? How can contemporary landscape design rethink the past and reveal the subtle traces left at an historical or archaeological place? How does memory, as a mind process, inflect our perception of landscape and influence our interventions and thoughts about it?

Each project engages with the relationship of landscape design to memory using an array of different design tools.

\section{Landscape, place and identity-The genius loci}

landscape is a repository of memory both individual and collective ... [and] is a site of and for identity

-W.J.T. Mitchell

Landscape architecture, when understood as a means to culturally define place, is a vast interdisciplinary field that addresses the relationship between the built and natural environment. As a common ground between urbanism, architecture and ecology, landscape architecture tries to respond to current issues of sustainability and environmental decline, but is equally concerned with questions concerning culture, identity and aesthetics. 
The crucial difference between landscape architecture and scientific fields that investigate aspects of landscape is that the former focuses on the processes of space formation in relationship to scale, time and topos. It is concerned with the cultural and spatial organisation of place as a dynamic continuum that, according to functional programs and natural ecosystems, is constantly changing. Landscape architecture is the intermediate layer of transformation between nature and culture. When we look at a landscape, we are looking at something that is forever changing both physically and visually. The interaction between human action and the natural characteristics of a site create landscape, which is understood in this context as the cultural expression of a civilisation.

Theorist Christian Norberg-Shulz, when discussing the concept of genius loci, speaks of architecture as making concrete the nature of a place. He says that human-made places relate to nature in three evolutionary ways: first, human beings visualise an understanding of nature; second, humankind symbolises this understanding; and, finally, humankind uses this understanding to create a micro-cosmos. In Elements of Visual design in the Landscape, landscape architect Simon Bell writes:

Genius loci, or the spirit of the place, is that quality or characteristic which makes one location or landscape different from any other, and that is unique and individual to it. The concept is somewhat abstract and intangible and tends to be more commonly understood on an emotional and subconscious level. It is, however, a most important attribute in a place and may be fragile and vulnerable when changes occur in or around the particular location. (1993: 119)

In 'Being and time', philosopher Martin Heidegger discusses the concept of dasein, which he describes as being in space. The world is experienced through our bodies; the physical world is an integral part of our existence and the basis of our perceptions. He adds that humankind is part of a fourfold continuum of earth, sky, mortals and divinities. In his essay 'Building dwelling thinking', he argues that, through dwelling, human beings place themselves in this fourfold continuum. He refers to the Greek word techne, which means to make something appear. For example, ancient Greek open-air amphitheatres are places where human creation and site form one landscaped whole through techne, one cultural entity below sky.

Simon Bell also says that place is important to us and our lives because our sense of identity may be bound up with a particular place and we may refer to ourselves by reference to particular places. Place itself consists of the totality of the natural and constructed elements, assembled in a unique manner that includes the history and associations attached to the place by the people who relate to it. 
For landscape architecture, education and practice, attention to 'landscape identity' is seen as part of a professional ethos; it has a special value. Landscape identity has two aspects: one has to do with the physical features of a site that give it a special spatial character and the other refers to the relationship of human beings to a specific landscape and what it means to them. Derk Stobbelaar and Bas Pedroli define landscape identity as 'the unique psychosociological perception of a place defined in spatial-cultural space' (2011). They explain that 'social-cultural meanings that are linked with places, features or events in the landscape, play a role in the collective living world and confirm the "we-feeling" of a group'. Landscape identity is a key issue for them and they add that the 'characteristic features of a landscape, rooted in time, visible and recognisable, distinguish the landscape from other landscapes and play a role in the collective living environment'. Without people connected to them, landscapes are no longer living places.

A landscape may be a physical space for living, but it is also a place with social meaning. 'Place', anthropologist Marc Augé asserts, 'can be defined as relational, historical and concerned with identity'. Accordingly, the specificity of a place makes it a reference point and source of identification for citizens. Augé's concept of place is clearly charged with emotion and memory. Opposed to a place is the concept of a non-place. This is described by Augé, as a 'space which cannot be defined as relational, or historical, or concerned with identity' and is consequently devoid of emotion and memory. In it, social interactions and emotional attachment fail and give way to individualism. An example is a supermarket, which is devoid of local identity and might be constructed in any place of the world. As he notes, the 'space of non-place creates neither singular identity nor relations; only solitude'.

At the 2010 Conference of the International Federation of Landscape Architects in Santiago, Chile, it was claimed that 'landscape architecture is a discipline cherishing and protecting the geographical identity of a place' (Howard, Thompson and Waterton 2013: 274). Furthermore, the European Landscape Convention states that landscape "contributes to the formation of local cultures and ... is a basic component of the European natural and cultural heritage, contributing to human well-being and consolidation of the European identity'. It is not only that landscape represents cultural identity, but that it also serves as an identity builder.

The need for research into the places where individuals might interact and create a common feeling of belonging is more crucial than ever. In Sentimental Topography, the visionary Greek landscape architect Dimitris Pikionis explains:

We rejoice in the progress of our body across the uneven surface of the earth. And our spirit is gladdened by the endless interplay of the three dimensions that we encounter in every step ... You compose the diagrams of this landscape. You are the landscape. You are the Temple that is to 
crown the precipitous rocks of your own Acropolis. For what else does the Temple do but enact the same twofold law which you serve? ... Is it not because of this concordance, because the same laws are at work in both nature and art, that we are able to see forms of life, forms of nature transformed before our very eyes into forms of art and vice versa? (1989: 68)

Pikionis eloquently describes the close sensorial relationship between human beings and the landscape that is walked and experienced: topos and person becoming one entity.

\section{Memory and its relationship to topos}

The American Nobel prize-winning neuropsychiatrist Eric Kandel has claimed that knowledge and memory are the centres of gravity of our personal identity, they make us what we are:

In a larger sense, memory provides our lives with continuity. It gives us a coherent picture of the past that puts current experience in perspective. We are who we are because of what we learn and what we remember ... Memory is essential not only for the continuity of individual identity, but also for the transmission of culture and for the evolution and continuity of societies over centuries ... loss of memory destroys our sense of self. It severs the connection with the past and with other people. (2006: 10)

In Europe, the concept of memory is always located in an historical context and is strongly linked to a sense of place. Landscape architect Christophe Girot says that the landscape precedes the landscape architect, yet architecture can never precede the architect. As landscapes contain the palimpsest of human actions over time, they are also carriers of the past. Finding a way of keeping a memory 'alive' is an act of resistance to losing our identity. The same stands for landscapes of memory. Landscape design in this sense should be the stabiliser of meaning, an intermediary keeping memory in a continuous recall. A wellpreserved or designed landscape provides a psychological anchor between us and the world. Without this connection with the landscape, the individual can feel rootless. Landscape can provide a tangible link between what we are and what we have become.

Landscape and memory are concepts that are strongly interwoven with the identity of a place and its inhabitants. Local myths, associations, habits and rituals, shared fears, collective memory and common feelings are all intangible elements of a place that give it a certain allure and atmosphere, its sense of place, its genius loci. It is not only how a place is but also how it makes us feel, how we live and perform in it. 
In On Collective Memory, the French sociologist Maurice Halbwachs suggests that a social group's identity is constructed out of narratives and traditions that are created to give its members a sense of continuity, a sense of belonging. The term collective memory includes the myths, traditions and beliefs that tie people together. Individual memory refers to personal events, while collective memory contains events that were transmitted to the individual by other members of the society, it is a mutual memory that concerns us all, which is why it is so important. Halbwachs also says that individual memory is personal, while collective memory is a framework on which we can relate and contextualise our memories. He suggests that our memories gain significance only in relation to collective memory; that is, a kind of memory living beyond the individual. $\mathrm{He}$ adds, however, 'While the collective memory endures and draws strength from its base in a coherent body of people, it is individuals as group members who remember' (1992: 48).

\section{French historian Pierre Nora says:}

We speak so much of memory because so little is left ... Our interest in lieux de mémoire, where memory crystallises and secretes itself, has occurred at a particular historical moment, a turning point where consciousness of a break with the past is bound up with the sense that memory has been torn-but torn in such a way as to pose the problem of the embodiment of memory in certain sites where a sense of historical continuity persists. There are lieux de mémoire, sites of memory, because there are no longer milieux de mémoire, real environments of memory. (1989)

Nora observes that there has been a shift from 'a natural, collective memory'milieux de mémoire - to a more 'conscious way of maintaining memory' that has to do with intervention on specific sites-lieux de mémoire. The fact that in lieux de mémoire memory serves as a spectacle for the modern city could lead to a kind of contemporary loss of memory. This observation on the one hand emphasises the importance of designing memory spaces but, on the other hand, implies that the role of natural memory could be unintentionally minimised.

The lack of a dynamic active memory creates our interest in sites where memory recurs, places that give us a sense of continuity. Memorial sites are needed because of the lack of a spontaneous automatic and genuine memory. Places that are designed as memory archives, as memory landscapes, have to exist in order to be the spatial testimonies of our lost collective memory.

English writer Margaret Drabble declared, 'This is one of the reasons why we feel such a profound and apparently disproportionate anguish when a loved landscape is altered out of recognition; we lose not only a place, but ourselves, the continuity between the shifting phases of our life'. Landscapes of memory are not functional places but places that express ideals that carry meanings. The tangible and intangible aspects of collective memory can subconsciously inflect the landscape design process. As historian Simon Schama writes in 
Landscape and Memory, 'Before it can ever be the repose for the senses, landscape is the work of the mind. Its scenery is built up as much from the strata of memory as from layers of rock'.

\section{Landscape design as a lens for reinterpreting the past-On designing landscapes}

How can we activate latent characteristics of a landscape that are connected and refer to past times? How may memory, as a mind process, inflect our perception of landscape and influence our interventions on it? The interesting issue is not only to respond to the question of what landscape is as a concept, but also to explore how to design landscapes and invent ways of revitalising and transforming them through reference to the past.

'Landscape' is not merely a philosophical term or a spectacular view of nature, it can also be a design product, an intervention on a large scale, or a project with biological infrastructure. It seems that landscape design is a cultural act of incorporation and compositional weaving together of all the parameters that characterise a site: morphology, hydrology, ecology, scale, vulnerabilities and latent dynamics, as well as local myths, beliefs and atmospheres-in totality, the genius loci. The landscape designer usually works with these aspects of a place in order to reinterpret it. Simon Bell explains:

... genius loci is an elusive quality which tends to be easier to conserve than to create. It is certainly vulnerable to damage or destruction if not recognized or valued and treated with sufficient sensitivity. People tend to be more attached to a landscape with a strong sense of place and so are more likely to be sensitive to and wary of landscape change. An essential part of the analysis of any landscape should be to try to identify the genius loci. (1993: 122)

If we assume that landscape design can translate these complexities and different layers of meaning, then we could claim that in order for a project to belong to an historical place it must respect and reinterpret the history and past memories recorded there. Monuments and an historical built environment help people to remember, or not to forget. Preservation of place ensures that it is possible to associate it with past events and to maintain historical continuity across time.

The next section explores the way in which landscape, identity of a place and memory interact through design and design's visual and material form, using examples from professional and educational projects. 
The projects selected vary in scale, context, situation and historicity, but share concern for the issue of how contemporary landscape design can rethink the past and reveal the subtle traces of the past that remain at an historical or archaeological site.

\section{Example A: Redesigning Eleftherias Square, Thessaloniki- 'The time tissue'}

Competition entry: 12th shortlisted selection among 145 entries

Design Team: $\quad$ Katerina Andritsou, architect/landscape architect; Panita Karamanea, architect/landscape architect; Athanasios Polizoidis, architect/landscape architect

Collaborators: $\quad$ Errikos David, lighting expert;

Elias Kaboukos, installations expert

Students: $\quad$ Xenia Papatriantafillou, Marintina Kardarakou

April 2013

Time is rather a boundless landscape and what moves is the observer's eye. -Thornton Wilder

Eleftherias (freedom) Square is a unique place of collective memory for the city of Thessaloniki. Urbanity, history and memory are strongly attached to this place, giving it deep symbolic meaning. At the beginning of the twentieth century, the square was an urban space of leisure. It was burnt in the great fire of 1917 (which destroyed much of the city) and was witness to many historical events that occurred between the two world wars. One of the darkest historical events took place during the Second World War when German soldiers forced local people into the square before transporting them to concentration camps. This dramatic event stigmatised the square and, eventually, collective memory came to regard it as a 'cursed place'. The cruel historical events became a burden for the site, which ended up a leftover space, a terrain vague that functioned as open-air parking. The square, however, situated as it is in the centre of the historical old city and in front of the waterfront, is extremely beautiful.

In the spring of 2013, the municipality of the city announced an architectural competition to redesign the square in order to reclaim this ambiguous terrain as an active urban space.

This is an example of when a place, although it possesses a strong collective memory, has lost its physical form as well as its capacity to engage people in thinking about its past functions and associations. It seems that it requires the 
activation of the qualities that are inherent in the site in order to unlock the latent genius loci. How can landscape design reinvent a particular place within a city; how can a place of the past come alive for the present and the future?

The sense of loss forms an opportunity for urban revival and spatial cohesion; this ambiguous and awkward terrain needs to be rethought with consideration for the relationship between this landscape and memory. The intervention sought to create a contemporary European urban space that revealed the genius loci. The particular memories associated with the site and its temporal relationships gave birth to the main idea.

Time was the starting point: time as an ephemeral instant, as a continuing sequence of metropolitan events, as an historical moment. Temporality, fluidity, intertemporal facts. Time here is understood according to three modalities: as history and its relation to collective memory; as ecology, including the cyclical time of nature and the four seasons; and as urbanity, the ephemeral leisure time of the contemporary metropolitan inhabitant. Time was acted on as a unifying tissue, a time tissue.

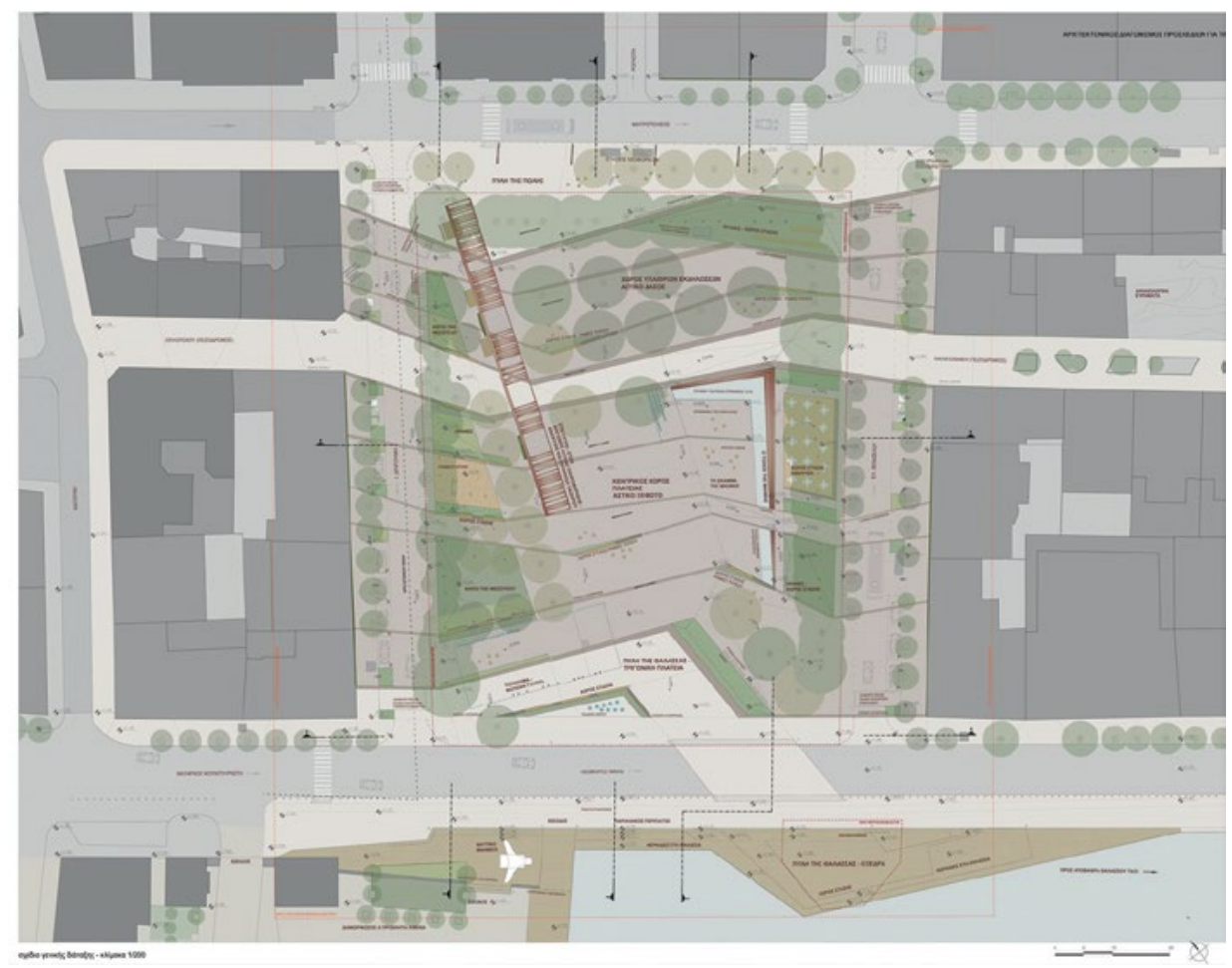

Figure 1. Masterplan

Source: Panita Karamanea 
The main spatial tool of the design proposal was the surface of the square and its sections; horizontal planes constructed from different local stones in longitudinal layers that weave from side to side, giving a sense of fluidity to the site through flowing lines that stretch and divide the square into three functional zones while, at the same time, creating a unified space.

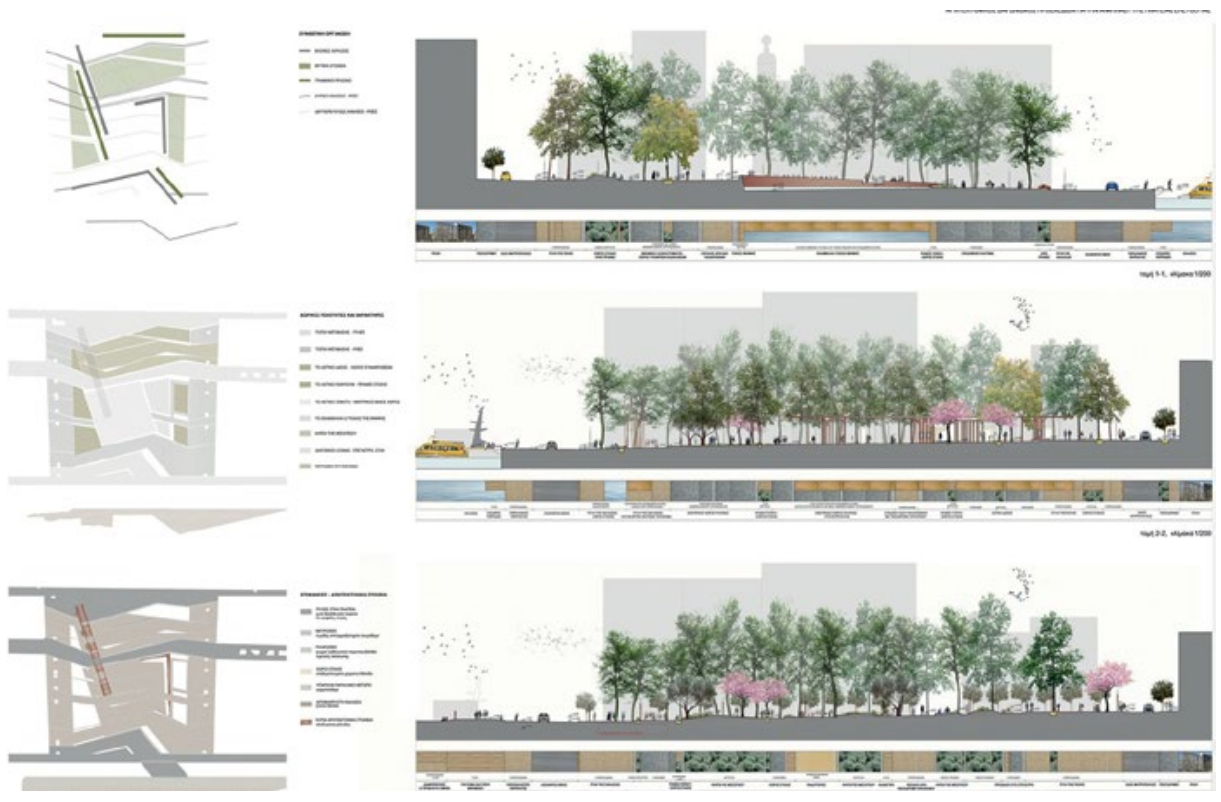

Figure 2. Diagrams and sections

Source: Panita Karamanea

The dominant compositional element was the void left in the centre of the square, symbolising loss. On the edges of the square, tall existing trees form an urban forest in the middle of which is a clearing. It is an open space from which the sea, the horizon and the surrounding built landscape of the old city are visible: a free and open space in which to just be. The surface of the square runs up against a sculptural memorial wall, an anti-monument, that seems to draw the ground into it.

The intervention has a strong Mediterranean aspect. Proposed plantings are local species that demand little irrigation, thereby helping to rejuvenate the existing ecology. The existing trees, which are the main focus of the square, are maintained, while secondary trees are proposed to emphasise the project's spatial structure. Vegetal borders form mild filters for the surroundings, and a series of small-scale Mediterranean garden habitats complement the project. 

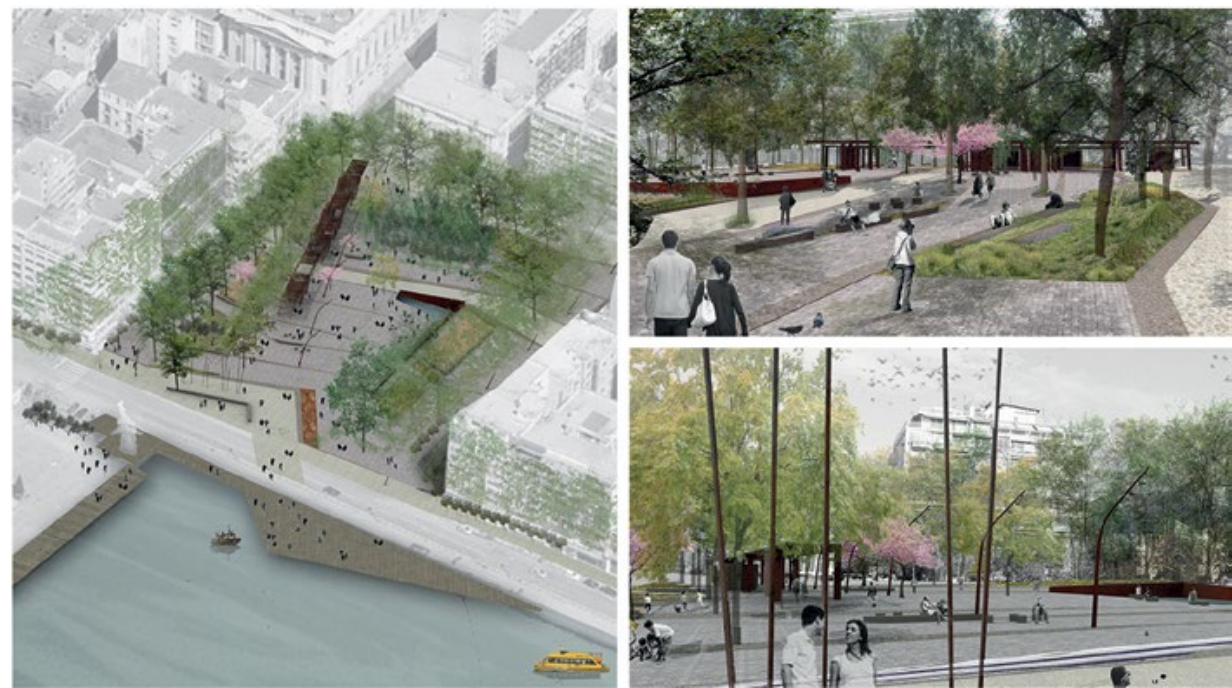

Figure 3. Photomontages

Source: Panita Karamanea

\title{
Example B: Eptapirgion area, Thessaloniki- 'Ecological histories'
}

\author{
Competition entry: 4 th prize \\ Elena Kouri, architect \\ Collaborators: $\quad$ Errikos David, lighting expert \\ Student: $\quad$ Xenia Papatriantafillou
}

Design Team: $\quad$ Panita Karamanea, architect/landscape architect; Athanasios Polizoidis, architect/landscape architect;

November 2012

In wilderness is the preservation of the world.

-Henri David Thoreau, 1862

Eptapirgion is a medieval castle acropolis on the north-east border of Thessaloniki. It is situated on a small hill, surrounded by parts of the medieval wall that once protected the city. In the medieval era, the castle defended the city but, in recent times, it functioned as a political prison. Collective memory has categorised it as a frightening and wild site, a place of imprisonment for the condemned that is beyond the scope of normal life and joy. The site of Eptapirgion, however, has a special identity and atmosphere, abundant natural beauty and astonishing views. Today, the site is wild, a protected cultural 
landscape where history meets the contemporary urban profile; it is a place that holds the city's heritage, waiting to be revealed. The castle stands at the top of a hill amidst patches of vegetation and meandering paths.

In November 2012, the municipality announced an architectural competition for the rehabilitation of the site. The project presented below won 4th prize.

Eptapirgion is an example of a site where the genius loci is very strong. The potent presence of the monument as well as the natural beauty of the terrain demands minimum interference. Any intervention should be discrete but legible. If this territory, which is so full of symbolism, is our materia prima, how can we maintain the sense of place and, at the same time, bring out the latent meanings of the site and create a contemporary urban space? The main inspirational concept was to maintain the site's genius loci as well as the existing vegetal wilderness.
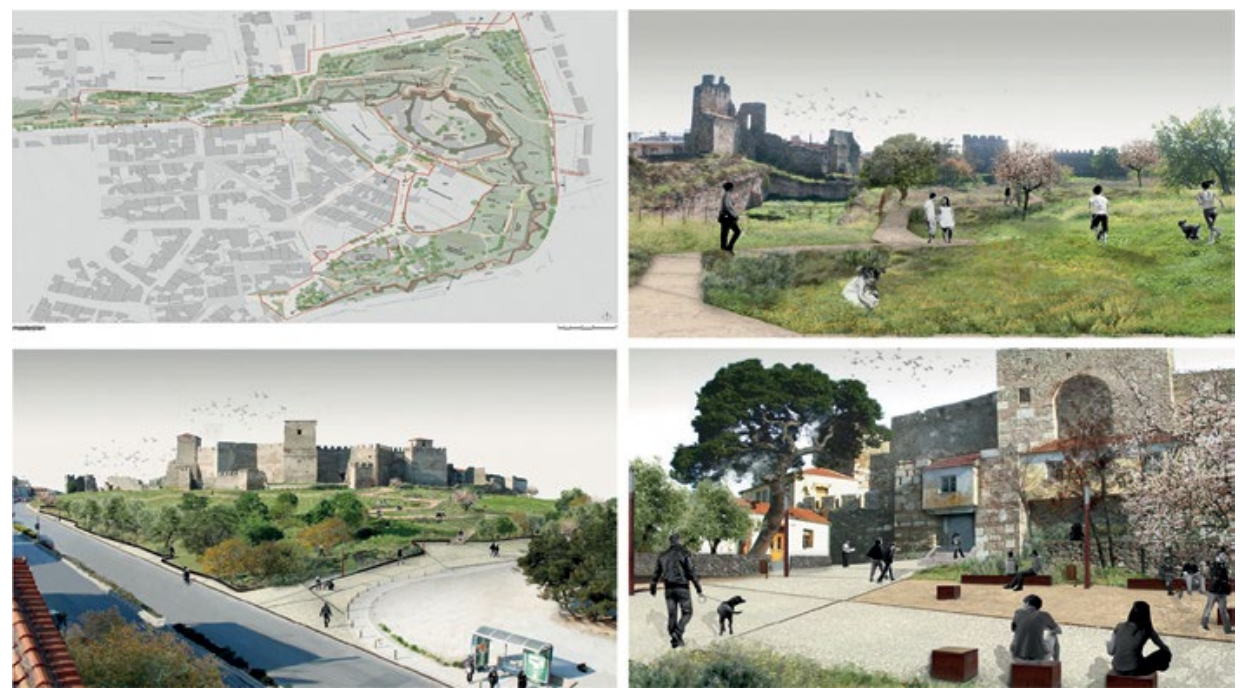

Figure 4. Masterplan and photomontages Source: Panita Karamanea

The goal was to create a mild green cosmos, a buffer zone between the city and the monument. The concept was derived from the defensive character of the existing walls and proposes a soft, planted mantle of protection and emergence; a filter between the city and an enclosed landscape. The intervention has a strong ecological-bioclimatic aspect and uses few elements to organise the place. The design concept is based on using natural processes, designing with nature and restoring wilderness. The design process focused upon:

1. Harnessing movements, flows and pauses in relation to the topography. The main compositional gesture is a network of dirt paths that enable an experiential narration of the landscape and the monument. The paths follow 
the topography and are connected with rest areas at key viewpoints near the walls, revealing the urban fabric, the mountain and the sea.

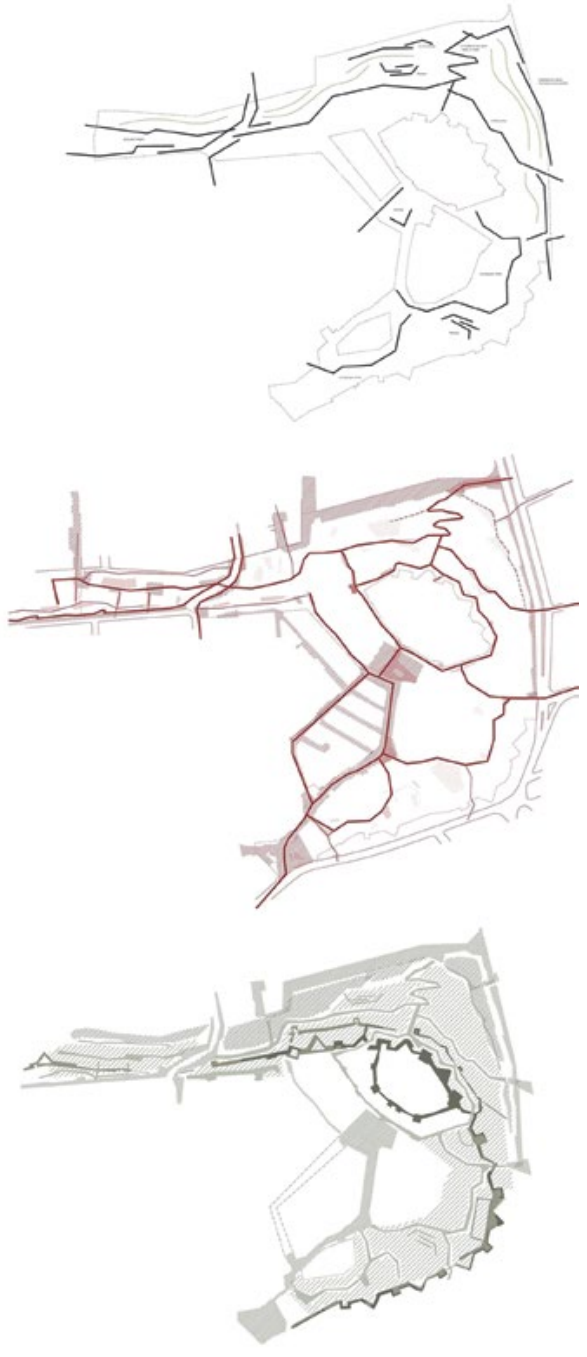

Figure 5. Diagrams

Source: Panita Karamanea

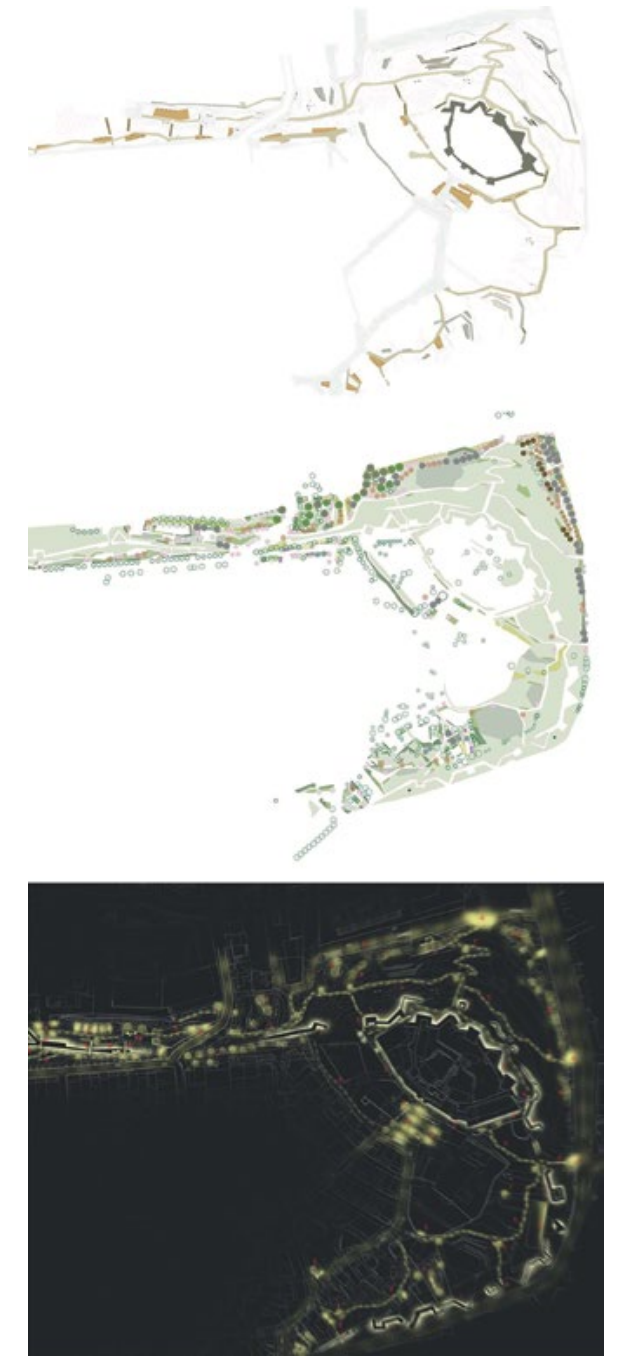

Figure 6. Diagrams

Source: Panita Karamanea

2. Creating a smooth vegetated mantle-filter that reveals and will gradually protect the monument and its surroundings. Local Mediterranean dryclimate species are used as they demand little irrigation and emphasise the site's austerity and symbolism. The design highlights the existing meadows, which are considered as free fields for natural regeneration. On the site's boundaries a filter of low evergreen trees is created for sound insulation and wind protection. 
3. The distinct spatial identities within the site are identified and emphasised: the meadow, the zigzag path, the viewpoints, the enclosed gardens, the linear park, the hidden amphitheatres, the path by the walls.

\section{Example C: Landscape design as an educational process- On teaching landscape}

Landscape design as a methodological tool in education is more and more useful for architectural studies. Landscape architecture as an interdisciplinary subject of research is particularly important for understanding the construction of culture and place, identities and space, environmental issues and habitats. Landscape architecture offers a holistic perspective on integrating environment with culture.

In his essay 'Nine rules for students of landscape architecture', French landscaper and educator Michel Corajoud advises that it is very important when visiting a site to sharpen personal observation. He insists that all information and answers are there, a priori. The only task for the landscaper is to pose the right question. A landscape project should try to awaken, to reveal and to underline by subtraction the strongest elements that form the identity of a place and to achieve these aims within a biological framework. Landscape architect Christophe Girot explains that the four steps necessary when approaching a site are: i) landing; ii) grounding; iii) finding; and iv) founding.

In recent years, landscape architecture has come to be of central importance for archaeologists in the European context. Archaeology, after all, is basically about three elements: material evidence, sites, and what can be understood from them. Landscape archaeology is the study of a terrain through the material remains of the past. The next example is about a sacred landscape in the countryside of Crete and the effort to decode the site through a diploma project.

Diploma project: The case of the Minoan Necropolis in Armeni, Crete'Time shortcuts'

School of Architecture, Technical University of Crete, Chania

Students: Hrisa Panagiotopoulou, Hristianna Fotou

Supervisors: Panita Karamanea, architect/landscape architect, lecturer in architectural and landscape design; Fani Tuffano-Mallouhou, archaeologist, associate professor of restoration

October 2013 
The quality of an artist depends upon the quantity of past he bears within him.

-Jean Gris

The project is an intervention in the late Minoan necropolis in Armeni-Rethymno, a protected archaeological site that is situated in a protected natural landscape in the countryside of Crete.

The extremely beautiful and vulnerable site is an ancient cemetery interwoven within a virgin landscape of oaks. The place is far from human settlement and the highway and it seems to have been forgotten among the quiet surroundings. The cemetery extends along a smooth slope where the ancient graves are present as holes in the ground; they are a series of perpendicular gaps in the landscape, burial cuts that have marked the site indelibly for centuries. In combination with the dense shadows from the old oaks, the place emits a sense of uncanny. It is a landscape intact since antiquity and collective memory regards it as an unusual site in the midst of the Cretan countryside, far from civilisation. The components of the site are minimal, potted with holes in the earth and planted with oaks, the question to be answered is how to intervene without damaging the atmosphere, in such a way as to be almost invisible. Using the language of landscape architecture, this diploma project researched how the spirit and identity of this site, where time seems to stand still, could be heightened while enabling it to remain relatively untouched. This is an example where the genius loci is symbolic and spiritual and the natural landscape exceptional and rare. It is a cultural landscape that requires small gestures: here, less physical alteration will achieve greater results.

The intent of the project was to heighten the qualities of the landscape by way of a subtle and reversible intervention, thus allowing visitors to understand and enjoy the special atmosphere of the place through the emergence of the natural landscape.

Each cultural landscape is a dynamic system, where space and time constitute an integral whole. The gradual decay of monuments over time leads us to consider time as linear rather than cyclic, while time in nature is experienced through the temporal cycles of the four seasons. This dual aspect of time and how it can be experienced through human movement became the basic tool underpinning the design intervention. 


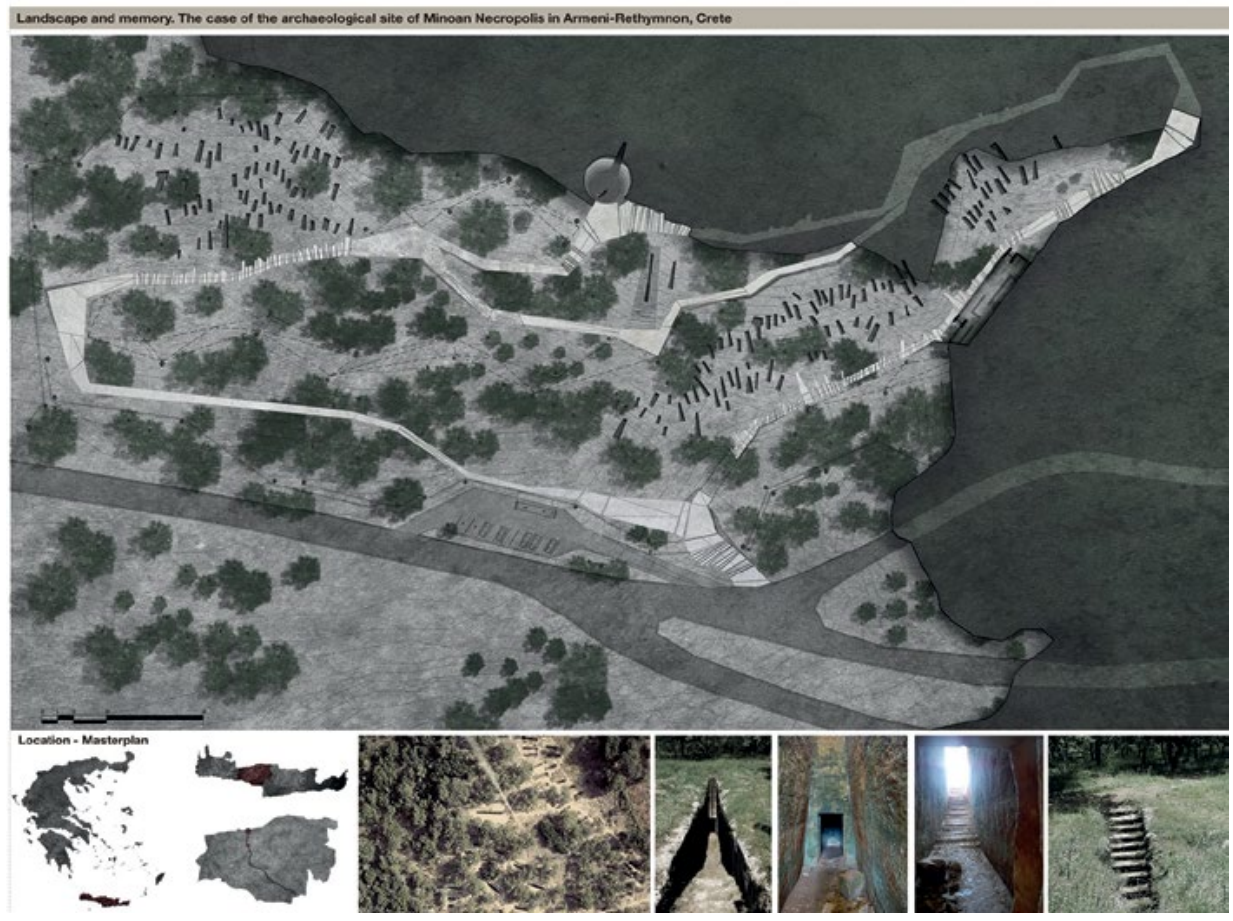

Figure 7. Masterplan

Source: Panita Karamanea

The basic structural element is a new path that introduces the visitor to the archaeological landscape by using the natural surroundings as elements of the project. The most humble elements of the landscape-twigs, clay, tree trunks, fallen leaves and rocks-are used with the same simplicity that prehistoric humans built their dwellings. Starting with the materials found at the site, delicate and reversible interventions are proposed that will disintegrate over time. The entrance to the archaeological site, formed by a cut into the ground, is a reminder of access to the graves, the old war pit (a hole in the ground used for defence) is converted into an amphitheatre that is sheltered by a wooden structure made from the existing trees, ancient deposition pits become spiral open-air museums for objects found at the site, light cloth double shell canopies that support climbing plants are proposed for the two largest tombs, and new viewing and sitting areas are designed to facilitate contemplation of the landscape. Simple archetypal forms from an ancient landscape, fragments of a whole, create a contemporary path that passes through the elements that evoke the history of the site, creating a contemporary landscape narration. 


\section{The dual aspect's of time - Diagrams}

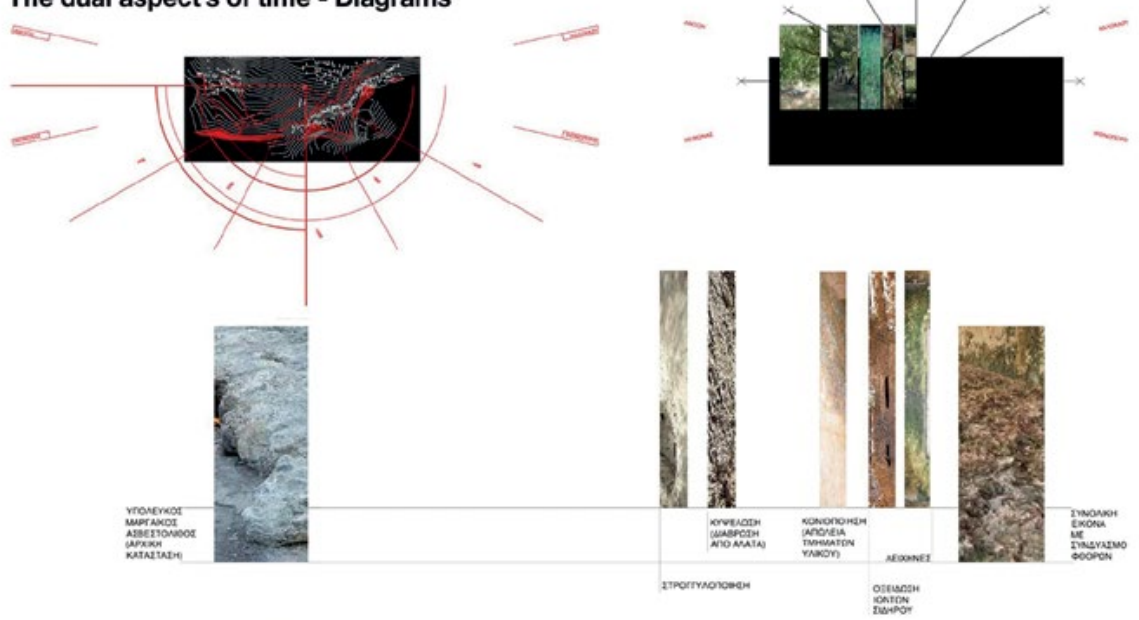

"Through the agency of this particular hour the mystery of time becomes one with the mystery of space. What irreconcilable elements have merged together here? Wherever one turns, one may see the double-headed hermae of antithesis. Faced with a mystery of this magnitude, the soul no longer needs an explanation, for in the deepening of nature's mystery, the soul undergoes a process, an experience, a 'passion' in the depths of which lies understanding." D. Pikionis, A Sentimental Topography, 1935

\section{The contemporary path}

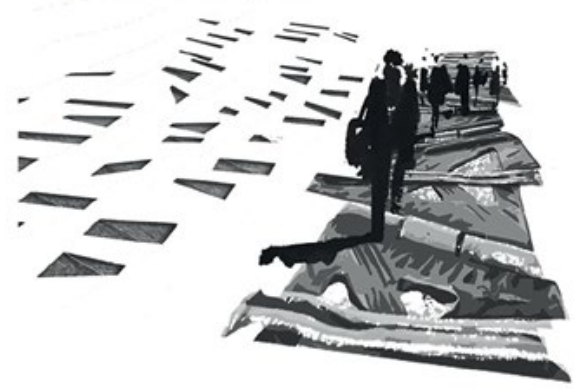

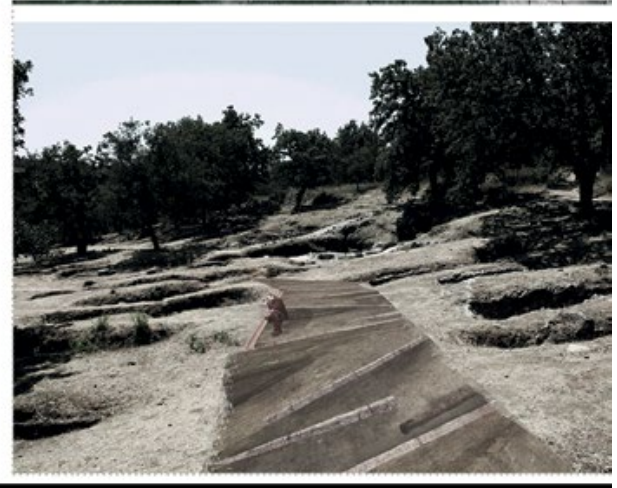

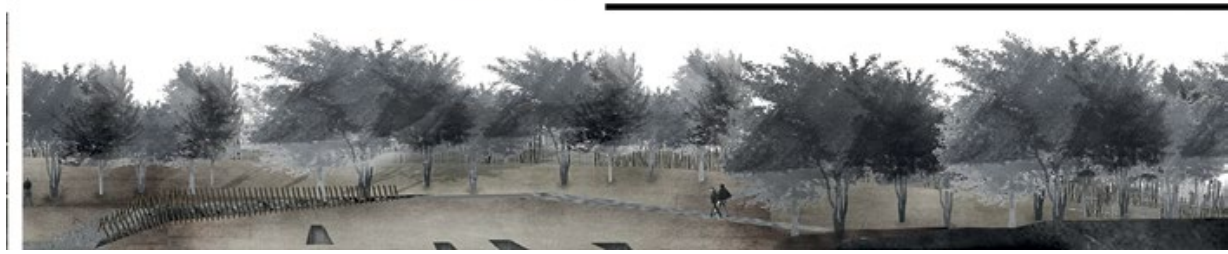

Figure 8. Diagrams and photomontages

Source: Panita Karamanea

Anthropologist Tim Ingold, in his essay 'The temporality of landscape', says:

For both archaeologist and the native dweller, the landscape tells-or rather is - a story. It enfolds the lives and times of predecessors who, over the generations have moved around in it and played their part in its formation. To perceive the landscape is therefore to carry out an act of 
remembrance and remembering that is not so much a matter of calling up an internal image, stored in the mind, as of engaging perceptually with an environment that is itself pregnant with the past. (2000: 189)

In having to deal with an archaeological landscape-an archaeo-scape-this project based its design process on walking and the natural potentialities of the site. Walking as a commemorative practice is used in order to awaken the relationship between visitor and place. Movement as a device for understanding landscape offers a varying conception of place, one which is continually shifting. A temporal landscape is being created, one that is best understood not from one point of view but when in motion. It is a spatial system to be experienced and revealed dynamically.

\section{Conclusions-Epilogue}

Landscape is the result of tension and equilibrium, it is dynamism, capable of transmitting emotion that goes beyond the visual.

-Manuel de Solà-Morales

Landscape design tries to balance dynamics in a constantly changing system where the sum of the parts is more important than the parts on their own. As a spatial syntax tool, it creates synergies and diagonal relationships between concept, context and ecology. But most of all, it is an open process of design related to time. Landscapes are always changing; they are in a constant state of becoming. Interventions in landscapes concern not only the creation of forms but organising the processes that give birth to them.

The examples presented in this essay show how topos, collective memory and genius loci influence projects in a creative way. Landscape design as a structural system organises, articulates, reveals, explains, reinterprets, protects and underlines the qualities of a site. A series of intangible concepts, such as collective memory and genius loci, as well as a series of tangible characteristics like topography, movement and plantation were addressed to varying degrees in each example.

In order to pay homage to collective memory and create an emotional landscape for Thessaloniki, the first example used a cut section to create a void within urban density. While the surrounding urban network is continuous, leaving an open space allows the project to evolve. Because of the scale of the site it is possible to maintain the existing void as a clearing in the city fabric. In the meantime, the design of the square's surface gives a new layer of meaning. By shaping the terrain and creating sections at different levels, the space, although empty, becomes sculptural. The eyes are directed downwards, paying homage to an allegoric immersion in the earth and the past: a section in space, 
a metaphorical section in time, a 'chrono-spatial fissure'. The project design proposes an architectural hardscaped version of landscape design in a central urban environment, using minimal symbolic elements.

The potential of ecology to act as a catalyst to rejuvenate a site on the city's edge is the design tool used in the second example. The existing wilderness means that the site has a compelling existing identity. The project in this instance was designed to modulate the unique qualities of the site in order to reveal and enhance it. Thus, landscape interventions function as a kind of 'acupuncture' that activates the a priori features, which means that a softer vegetated scheme is sufficient intervention. Ecological design and a network of paths is the missing agent that enables the existing poetic wilderness of this landscape to emerge. This is a softscaped approach that, by reactivating natural conditions, proposes the restoration of the site.

In the last example, walking as a narrative practice is the sensorial device that enables a visitor to experience a sensitive cultural landscape in the countryside. The ancient necropolis of Armeni is a vulnerable site; the past is still present here as the site has remained intact since antiquity. In this case, subtle and sensitive gestures are appropriate. The project allows for the dissolution of material forms while introducing subtle elements that are in tune with the natural environment and made from humble local materials.

All three projects use the surface of the earth as a basic tool: a solid ground that is gradually submerged, a vegetated soft ground that invites contemplation, an earthy excavated ground to be traversed. 'Earth to earth, ashes to ashes, dust to dust' says the Christian burial service, reminding us of the close bond that we have with the earth. It may be this strong subconscious relationship to the earth that leads us to sculpt the ground in a poetic way in projects having to do with the past. These projects also emphasise vegetation as a structural three-dimensional element. Plants, trees and soil are all parts of a narrative that creates spatial variety. Linear plantings or massed vegetation create spatial filters, visual borders and places to sit. Using perennial and deciduous species, a poetic effect is achieved as space dramatically changes with the seasons. Vegetation serves as a soft system for organising space, a living eco-material that varies through time. A third element in common is the use of movement in space: the act of walking. Walking becomes a narrative device that illuminates the site and its intrinsic qualities in a new way. The itinerary acts as an initiation to space, provokes emotions, presents different perspectives and views and leads the visitor through various spatial qualities. In this way, by engaging with the site through the sensory abilities of the human body, the interaction between the visitor and the landscape becomes a somatic experience. 


\section{In The Eyes of the Skin, architect Juhani Pallasmaa says:}

Sensory experiences become integrated through the body, or rather, in the very constitution of the body and the human mode of being. Psychoanalytic theory has introduced the notion of body image or body schema as the centre of integration ...

The body is not a mere physical entity; it is enriched by both memory and dream, past and future. Edward S Casey even argues that our capacity of memory would be impossible without a body memory ... We remember through our bodies as much as through our nervous system and brain. (2005: 40, 45)

Through walking and exploring, the human body gives life to a place, making it no longer a mute territory frozen in time but an animated landscape. Tim Ingold refers to bodily memory as an aspect of human memory that can evoke another kind of remembrance. He proposes the adoption of 'a dwelling perspective when thinking about landscape, according to which the landscape is constituted as an enduring record of-and testimony to - the lives and works of past generations who have dwelt within it and in so doing have left there something of themselves' (2000: 189). The past reaches into the present through bodily memory and human experience: looking, walking, listening, touching and smelling activate these memorial spaces and bring them to life again. Space and movement function as a catalyst.

Landscape architect lan Mac Harg says that natural phenomena manifest dynamically and depend upon physical laws and processes, we have to learn how all these phenomena function before deciding to intervene in a site. The interesting issue for a landscape architect is to find ways to incorporate into the design process the dynamic conditions of temporality and biological materiality that are found in it.

In order to reveal the genius loci, each project used a process of subtraction to reveal the strongest elements that formed the identity of each place. These integrated proposals are not imposed on or do not radically alter each site, they try to activate inherent qualities of each place but within a biological framework. In order to activate latent characteristics that are connected and refer to past times, all three projects try to create spaces that host a resilient coexistence of architectural and natural elements. Depending on the context and the necessities of each of these public spaces, the relation of hardscape to softscape varies. From city to countryside, the physical interventions required to bring out the hidden meanings of the site become less and less: an urban vegetated piazza in Thessaloniki, a monument's meadow in Eptapirgion, a natural architecture in Crete. Minimal elements, subtle sensitive gestures, the use of ecology as a mild living mantle, the ground as a relief of physical materiality, movement as a device of interaction with the site, are all landscape tools that try not to impose on these existing memory-scapes. 
By maintaining a landscape as untouched as possible, we leave room for individual and collective memory. The landscape designer rethinks the past and reveals the subtle traces left in an historical or archaeological place in order to enable the visitor to access the past through these traces. Landscape architecture, by using discrete design and ecology as a construction technique, is able to leave a soft footprint at a site and can organise space without burdening it by establishing designs that do not impose prevailing forms and propose without aggression. The integrated result can help us understand and perceive a vulnerable and precious landscape and be more likely to associate it with its past.

Landscape is equally a construction of the mind, a cultural archive, and an ecological warehouse. By linking landscape design research with practice and education, this essay has presented a range of design tools and results that activate the inherent qualities of each site.

Perhaps in the current era of environmental and economic crisis, hybrid landscape design practices that pay attention to intangible qualities like genius loci and memory are the only possible recourse to create culturally and ecologically sustainable environments.

Panita Karamanea was born and studied architecture in Athens and then continued her landscape studies in Barcelona. Her research interests are related to the relationships between landscape and built environment in order to find interactive tools of design integration. She has been teaching and practicing landscape architecture in Athens, Barcelona and Crete. She has participated in and won international and Hellenic competitions and shown in international exhibitions. She is currently lecturer of architectural and landscape design at Technical University of Crete, Greece.

\section{References}

Appleton, J., 1996, The Experience of Landscape, Wiley.

Augé, M., 1995, Non Places - Introduction to an Anthropology of Supermodernity, London: Verso.

Bachelard, G., 1986, The Poetics of Space, Beacon Press.

Bell, S., 1993, Elements of Visual Design in the Landscape, London and New York: Spon Press.

Gardens in Arms, 2001, catalogue of the 2nd Biennial of European Landscape Architecture, Barcelona: COAC.

Halbwachs, M., 1992. On Collective Memory, University of Chicago Press. 
Heidegger, M., 1971, Essay - 'Building Dwelling Thinking', in Poetry, Language, Thought, Albert Hofstadter (trans.), Harper \& Row.

Howard, P., Thompson I. and Waterton E., 2013, The Routledge Companion to Landscape Studies.

Ingold, T., 2000, The Perception of the Environment. Essays on Likelihood, Dwelling and Skill, London and New York: Routledge.

Kandel, E., 2006, In Search of Memory. The Emergence of a New Science of Mind, W.W. Norton \& Company.

McHarg, I., 1992, Design with Nature, John Wiley \& Sons.

Merleau-Ponty, M., 1982, 'Space', in Phenomenology of Perception, Routledge.

Nora, P., 1989, 'Between memory and history: Les Lieux de Mémoire', Representations, no. 26, special issue: 'Memory and counter-memory, pp. 7-24.

Norberg-Shulz, C., 1986, Architecture: Meaning and Place, Electa/Rizzoli.

—-, 1980, Genius Loci - Towards A Phenomenology of Architecture, Rizzoli.

Only with Nature, 2003, catalogue of the 3rd Biennial of European Landscape Architecture, Barcelona: COAC. Pallasmaa J., 2005, The Eyes of the Skin, John Wiley \& Sons Ltd.

Pikionis, D., 1989, Sentimental Topography, London: Architectural Association.

Remaking Landscapes, 1999, catalogue of the 1st Biennial of European Landscape Architecture, Barcelona: COAC.

Scharma, S., 1995, Landscape and Memory, London: Harper Press.

Stobbelaar, D.J. and Pedroli, B., 2011, 'Pespectives of landscape identity. A conceptual challenge', Landscape Research, vol. 36, no. 3, pp. 321-39.

Trieb, M., 1993, Modern Landscape Architecture: A critical review, MIT Press. 
This text is taken from Craft + Design Enquiry, Issue 7, 2015, edited by Kay Lawrence, published 2015 by ANU Press, The Australian National University, Canberra, Australia. 